\title{
Development of a sequential tool, LMDZ-NEMO-med-V1, to conduct global to regional past climate simulation for the Mediterranean basin: an Early Holocene case study
}

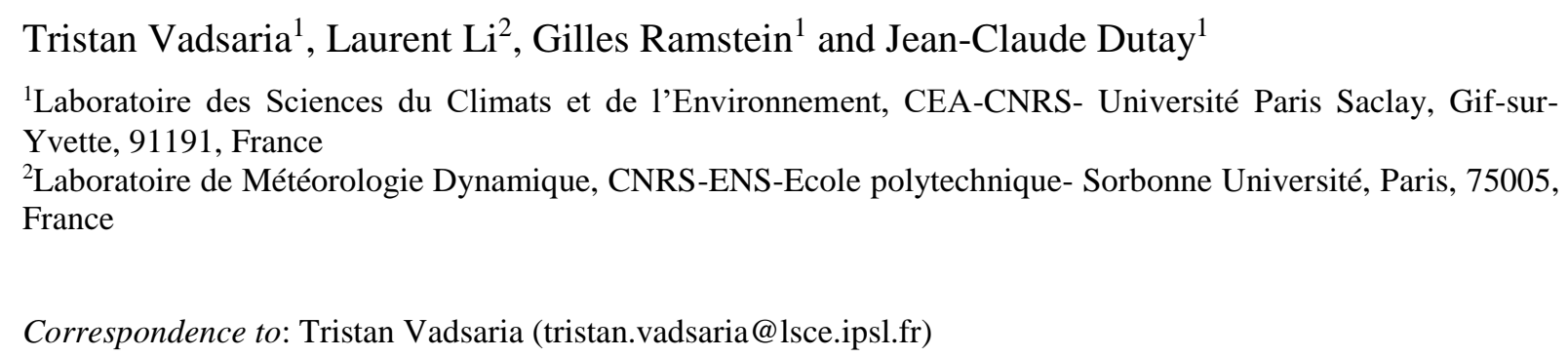

The supplementary material includes:

- Supplementary text

Text S1: LMDZ-NEMO-med, user manual

Text S2: Bias correction

Text S2: Comparison of model simulation outputs with reconstructed data for the whole Mediterranean basin

\section{- $\quad$ Supplementary figures}

Fig. S1. Comparison of model with data for continental precipitation

Fig. S2. Comparison of model with data for SST

Fig. S3. Comparison of model with data for SSS

Fig. S4. Interannual evolution of the IS over the Mediterranean Sea in the HIST simulation

Fig. S5. Interannual evolution of the ZOF in the eastern Mediterranean Sea in the HIST simulation

Fig. S6. Interannual evolution of the IS over the Mediterranean Sea in the PICTRL and EHOL simulations

Fig. S7. Interannual evolution of the ZOF in the eastern Mediterranean Sea in the PICTRL and EHOL simulations

\section{- Supplementary tables}

Tab. S1. Forcings and parameters used in both AGCM and ARCM

Tab. S2. Forcings used in the ORCM

Text S1: LMDZ-NEMO-med, user manual 
This section is intended as a user manual to provide an explanation on how to compile and run LMDZ-

NEMO-med on a Linux system. It is not, however, a detailed description of the source code. Files relevant to the running of the pre-industrial control simulation presented in the article have been archived and made publicly available for downloading: https://zenodo.org/record/3258410 (Vadsaria et al., 2019).

1 Atmospheric global model

LMDz4, used here in both the global and regional versions, is version 4 of the LMDZ model. It has the same major code structure and practical organisation as the last version, consultable on the web page: https://forge.ipsl.jussieu.fr/igcmg doc/wiki/DocImodelBlmdz

\subsection{Compiling the model}

The compiling environment is MODIPSL, a convention for code compilation when the code is distributed into different directories. The following directory should be consulted:

\section{“cd vadsaria_et_al_model/LMDZ_and_NEMOMED8_models/modipsl/util”}

Edit the "AA_make.gdef": the users should create a new entry to fit its computational architecture. Compiler options have been set up in this file and will be propagated to "Makefile" at different places.

It is recommended that all previous configurations be cleared by typing "./clr_make". A new configuration to match the right computer platform can then be created:

\section{“./ins_make -t NAME_OF_YOUR_ARCHITECTURE_SYSTEM"}

Before code compilation, netcdf and Fortran compiler need to be installed. FCM (Flexible Configuration Management: https://metomi.github.io/fcm/doc/), a tool developed by the UK Met Office to manage the dependence between different subroutines of a complex code is also required. Compiling options for FCM are stored under "machine/arch.path" and "machine/arch.fcm". They need to be coherent with what stored under "AA_make.gdef" and "Makefile".

To compile the code, the following directory needs to be consulted:

\section{“cd vadsaria_et_al_model/LMDZ_and_NEMOMED8_models/modipsl/config/LMDZ"}

Then, with the help of "Makefile", the following can be compiled: 
"Imdz96x71global" is a keyword found in the "AA_make" script allowing a configuration to be chosen.

If the compilation is successful, then the executable codes "create_etat0_limit.e",

"make_relax_times.e" and "gcm.e" are stocked at the following directory:

“cd vadsaria_et_al_model/LMDZ_and_NEMOMED8_models/modipsl/modipsl/bin”

\subsection{Running the model}

The first step is the creation of boundary conditions for the global atmospheric model. The files needed for this step can be found here:

“cd vadsaria_et_al_model/files_and_boundary_conditions_for_LMDZ_global/start_limit"

A boundary condition file is already provided in this directory: "limit_picontrol_debiais.nc". It is based on a bias-corrected file for SST and SIC data (following the procedure described in the main article) derived from the IPSLCM5 simulation for the pre-industrial simulation. The procedure to generate this boundary condition file is the following:

- Prepare a netcdf file with SST and SIC bias-corrected data, interpolated on a $1^{\circ} \times 1^{\circ}$ grid: "CM5piControl-pseudo_amip_1x1_tos_sic.3600-3699_climato.after_correction.nc" (in the subdirectory "/interpol", a code to generate a $1^{\circ} \mathrm{x} 1^{\circ}$ "AMIP" grid is provided : “interpol_ipslcm5_amip_tos_sic.F90”)

- Create symbolic links:

“In -s CM5-piControl-pseudo_amip_1x1_tos_sic.3600-3699_climato.after_correction.nc amipbc_sic_1x1.nc"

“In -s CM5-piControl-pseudo_amip_1x1_tos_sic.3600-3699_climato.after_correction.nc amipbc_sst_1x1.nc"

- Move the file obtained from the previous compilation of the model to the current directory and execute:

6./create_etat0_limit.e" 
This execution is based on a few ".nc" files containing information on topography, surface albedo, etc. It also takes relevant information from definition files of the model $(\mathrm{gcm}$.def, physic.def and orchidee.def. More information can be found by following the link mentioned at the head of the section). It should create a "limit.nc" file.

After creating the initial states and boundary conditions, we are now ready to run the model with an example from the following directory

“cd vadsaria_et_al_model/files_and_boundary_conditions_for_LMDZ_global”

The bash script "launch_picontrol_run_global_type" is an example of how to run the atmospheric global model. The script firstly organises files for boundary conditions and initial state (all presented in the current directory), and then executes the model "gcm.e" to generate outputs. This script was initially created for use in the supercomputing centre, TGCC, so instructions for the management of environmental variables, including the necessary pathways for the model's preferences and allocation of computing resources, are available. The script is executed with a time step of one month.

To start the execution of the model:

\section{./launch_picontrol_run_global_make 1}

"1" being the first month. It will create the launch_picontrol_run_global_launcher bash file. The user should then execute this file according to its system. If the script works, it will automatically generate the next iteration (the next month) until the maximum iteration is reached, denoted as the "stop" variable in the "launch_picontrol_run_global_type" file, set here at 360 months (30 years).

2 Atmospheric regional model

The code of this model is identical to that of the global version, but in "Makefile", the key word

Go to the following directory: 
Then compile the Makefile:

gmake lmdz200120_oneway

"Imdz200120_oneway" is a keyword found in the "AA_make" script allowing a configuration to be chosen.

If the compilation is successful, executable files found in the following directory can be applied:

“cd vadsaria_et_al_model/LMDZ_and_NEMOMED8_models/modipsl/modipsl/bin”

The first step is to create the boundary conditions for the regional atmospheric model. A boundary condition file, "limit_picontrol_debiais.nc", is already provided in the following directory:/vadsaria_et_al_model/files_and_boundary_conditions_for_LMDZ_regional/start_limit

It is of course different from that of the global model, but it is also obtained from a bias-corrected file of SST and SIC data, derived from the IPSLCM5 global coupled model for the pre-industrial simulation. The procedure to generate this boundary condition file is the same as described for the global version.

“cd vadsaria_et_al_model/files_and_boundary_conditions_for_LMDZ_regional”

The example bash script "launch_picontrol_run_regional_type" shows how to run the atmospheric regional model. Unlike the global model, additional files are needed to nudge the regional model with the global output. "biline_poids_s.nc", "biline_poids_u.nc" and "biline_poids_v.nc" (presented in the current directory) are interpolation files allowing efficient transformation of global variables for the regional model grid. Nudged forcing, with a 3-hour time step, from the global model is stored in "sortie_histfrq.nc.

Since the global and regional models share a common structure, their launch is also very similar,

3 Mediterranean oceanic model 
The compilation of NEMOMED8 is managed entirely through MODIPSL, so the generation of Makefile is the same as described earlier for LMDZ. The keyword to be used in the argument of "gmake" is "nemomed8". The compilation procedure is simply the following:

“cd vadsaria_et_al_model/LMDZ_and_NEMOMED8_models/modipsl/config/NEMOMED8”

"gmake nemomed8"

“cd vadsaria_et_al_model/LMDZ_and_NEMOMED8_models/modipsl/modipsl/bin”

If the compilation is successful, then it creates the executable file, "opa". In our study, NEMOMED8 is compiled to run with 121 cores in parallel mode.

Before running the model, the 3D boundary conditions for salinity and potential temperature over the buffer zone in the Atlantic close to the Gibraltar need to be generated. This operation is conducted in the following directory:

\section{“cd vadsaria_et_al_model/files_and_boundary_conditions_for_NEMOMED8"}

These boundary conditions are found in the files

"data_1m_potential_temperature_nomask_picontrol_debiais_climato.nc" and “data_1m_salinity_nomask_picontrol_debiais_climato.nc", bias-corrected from the IPSLCM5 preindustrial simulation. The grid of the NEMOMED8 model ("meshmask_med8.nc") is provided allowing the user to interpolate their own boundary conditions from this grid.

The second step is to generate the surface fluxes from the atmospheric regional model. For this purpose, a bilinear interpolation is used to convert the LMDz4 air-sea fluxes into the NEMOMED8 grid. For this purpose, an interpolation is used to convert the LMDz4 air-sea fluxes into the NEMOMED8 grid (bilinear for wind stress and conservative remapping for other fluxes). For NEMOMED8, the water, radiative, latent, sensible fluxes and wind stress are required. In the subdirectory "/lmdz_to_nemo", a code is provided to generate the bilinear interpolation scheme: "interpol_between_lmdz_et_nemo.F90". During the execution of the executable file, a weight file is required ("opalmdmo", also provided in the sub-directory). 
“sst_picontrol_debiais.nc.000101",

“flx_picontrol_debiais.nc.000101”,

“taux_picontrol_debiais.nc.000101" and

“tauy_picontrol_debiais.nc.000101”.

Finally, the bash script "launch_picontrol_run_mediterranean_ocean_type" is an example of the instructions necessary to run the oceanic regional model. The procedure is similar to the global and regional atmospheric model.

\section{Text S2: Bias correction}

The bias correction for our experiments driven by IPSL simulations is illustrated. IPSL-CM5A is a fully coupled climate system model. It operates autonomously for either present-day climate, future climate scenarios, or paleo climate reconstructions, depending on the external forcings or boundary conditions imposed on it. For its historical simulation of modern climate (from 1850 to 2005), we point out a few general biases that need to be corrected before running our regional system for paleo periods (Early Holocene). Below, the correction method for the oceanic 3-D structures: SST and SIC; as well as, the freshwater discharges from rivers, is described.

The global fields of SST and SIC are the most important variables in our methodology since they contain the main climate change information to be transferred from the global scale to the regional scale. They are used to force both the AGCM and the ARCM. SST has a cold bias globally that has a strong impact on the Mediterranean Sea and the nearby Atlantic region. To remove this bias, we simply applied an offset based on the difference between the IPSL-CM5A historical simulation and the ERA-Interim reanalysis (Dee et al., 2011) for the period 1970-1999.

IPSL-CM5A, on the other hand, tends to overestimate temperatures at the poles, which leads to an underestimation of the SIC. This bias affects the surface albedo and the global energy budget. It also affects the meridional temperature gradient and consequently the mid-latitude atmospheric eddies. The bias correction used for SIC is the analogue method presented in Beaumet et al., (2017). The basic idea is to adjust the total areas covered by sea ice for each hemisphere and for each month following the geographic and temporal biases. As with the previous corrections for SST, the hemispheric and monthly bias correction for SIC is based on the difference between IPSL simulations and observed SIC 
of SIC is determined by hemisphere and by month following an analogue relationship extracted to match observations from 1970 to 2012.

\section{$3 D$ temperatures and salinities in the buffer-zone}

The 3-D fields of oceanic temperature and salinity (over the whole water column) in the Atlantic buffer zone has been adjusted in the same way as for SST. We used the World Ocean Atlas (WOA) (Locarnini et al., 2013) as a reference to correct the outputs from the IPSL-CM5A historical simulation.

\section{River runoff to the Mediterranean Sea}

Freshwater discharge from rivers around the Mediterranean Sea is an important factor controlling the overturning circulation of the Mediterranean. Due to the high sensitivity of oceanic circulation to this variable, we decided to apply a correction based on Ludwig (Climatology 2009) modified using simulated precipitation anomalies between Early Holocene and present day. Since the atmospheric model (LMDZ4, and especially the regional configuration, LMDZ4-regional), coupled to the land surface model, ORCHIDEE, tends to overestimate the amount of freshwater runoff in LMDZ4 compared to present-day observations, we applied a bias-correction with observed climatological runoff. When the difference is not significant, the corrected runoff is set to the climatology, mainly to avoid negative values $^{1}$. However, in order to stay consistent with the methodology for SST and SIC bias correction, we chose the absolute difference correction method for the river runoff. This correction is based on the monthly difference between LMDZ4 runoff and climatology (Ludwig et al., 2009; Vorosmarty et al., 1998).

\section{Text S3: Comparison of model simulation outputs and reconstructed data for the Mediterranean basin}

\section{Continental precipitation}

The reconstructed data used for the comparison with the EHOL simulation is taken from Dormoy et al., (2009) for the Aegean Sea, from Peyron et al., (2011) for the Lake Accesa and from Tenaghi Philippon, and Magny et al., (2013) for Lake Pergusa. In these studies, continental precipitation is reconstructed based on pollen sequences to emphasis the changes in precipitation seasonality. Several methods are used to determine these changes. We chose to reconstruct these changes using the Modern Analogue Technique (MAT, Guiot, 1990), because, in their study, Magny et al. compared their data to Peyron et al's MAT. We extracted data values framing a few hundred years around $9.5 \mathrm{ka}$ cal BP, because the

\footnotetext{
${ }^{1}$ Namely, when the difference does not exceed $25 \%$, of the annually average annual difference for the Nile river runoff (due to the simulated amplitude, cf section 4.4 ) and $5 \%$ for the rest of the rivers.
} 
orbital parameters of our atmospheric simulations (both global and regional) were set as they were during this period. For the Northern Sahara, data are based on $\delta^{18} \mathrm{O}$ from Bar-Matthews et al., (2003).

Comparison between model outputs and data in terms of annual and seasonality changes can be conducted and anomalies against modern values can be shown. In winter, the model shows positive precipitation anomalies for the four sites (Lake Accesa, model: $+20-36 \mathrm{~mm}$, data: $+20-40 \mathrm{~mm}$, Tenaghi Philippon, model: $+30-45 \mathrm{~mm}$, data: $+10-35 \mathrm{~mm}$, Aegean, model: $+29-45 \mathrm{~mm}$, data: $+10-80 \mathrm{~mm}$, Lake Pergusa, model: $+7-26 \mathrm{~mm}$, data: $+35-60 \mathrm{~mm}$, figure 1 , a d g i). In summer, the model shows a more contrasted response, with negative anomalies in summer temperatures (Figure 1, b e, h, j) due to the homogenous drought (fig $8 \mathrm{~d}$ in the main article). However, this comparison cannot reflect the precipitation changes for the entire continent. Indeed, north of Lake Accesa we see positive summer anomalies (fig $8 \mathrm{~d}$ in the main article). Our model underestimates precipitation over northern Sahara and northern Africa as do most Mid and Early Holocene simulations. As mentioned earlier, the LMDz model cannot reproduce the northward shift of the last African Humid Period, leading to an underestimate of precipitation.

\section{Sea Surface Temperatures}

We conducted a comparison of model output and data for SST as Adloff et al., (2011) did with the reconstruction of Kucera et al., (2011) (unpublished work). This reconstruction is based on census counts of foraminiferal species, and on the artificial neural network for the transfer function. The data used span the Holocene Insolation maximum interval (8.5 - $9.5 \mathrm{ka} \mathrm{BP}$ ). Winter SST values (January to March) are a bit lower than the reconstruction figures especially for the Eastern basin ( -1 to $\left.-2{ }^{\circ} \mathrm{C}\right)$. The simulated summer SSTs (July to September) are higher between the Tyrrhenian Sea and the Levantine Sea $\left(+1\right.$ to $\left.+4{ }^{\circ} \mathrm{C}\right)$. This enhanced contrast between winter and summer values for simulated SST produced an annual signal in good agreement with the reconstructed values. Our results depict the same signal pattern as the simulations of Adloff et al., 2011, with some difference in the enhanced seasonal contrast.

\section{Sea Surface Salinities}

The comparison of SSSs over the Mediterranean Sea provides an appropriate indicator of freshwater perturbation induced by enhanced river flux. In order to perform the comparison, we used a synthesis (Kallel et al., 1997) of SSS values sampled from the S1 deposition. Our EHOL simulation takes the Nile river enhancement into account, $13000 \mathrm{~m}^{3} / \mathrm{s}$ annually $\left(2930 \mathrm{~m}^{3} / \mathrm{s}\right.$, pre-industrial value), and the NorthEast river margin enhancement (Buyukmenderes, Vardar, Acheloos, Vjosa, Semanit, Shkumbin, Durres, Mat and Drini), for a total of $1622 \mathrm{~m}^{3} / \mathrm{s}$ annually and $3228 \mathrm{~m}^{3} / \mathrm{s}$ from February to May $\left(1082 / 1619 \mathrm{~m}^{3} / \mathrm{s}\right.$ 
pre-industrial), inferred from the precipitation anomalies of the regional atmospheric model. Our EHOL

319 simulation, even using the strongest freshwater input, cannot reproduce a decrease in SSS sufficient to

320 match the reconstructed values, as shown in figure S3. This reflects the results of Adloff (2011). Indeed,

321 as demonstrated by Rohling $(1999,2000)$, this mismatch can be partly attributed to salinity

322 reconstruction. It is not always straightforward to interpret the isotopic composition of oxygen in terms

323 of salinity. Finally, it is likely that an additional non-negligible fresh water source is missing. To explain

324 the substantial SSS decrease, an additional source of freshwater associated with an amplification of the

325 flux of the North African rivers could potentially be superimposed on the Nile. Indeed, changes of this

326 type in the hydrology are clearly indicated by the data but are not reproduced in most of the Early and

327 Mid-Holocene simulations.
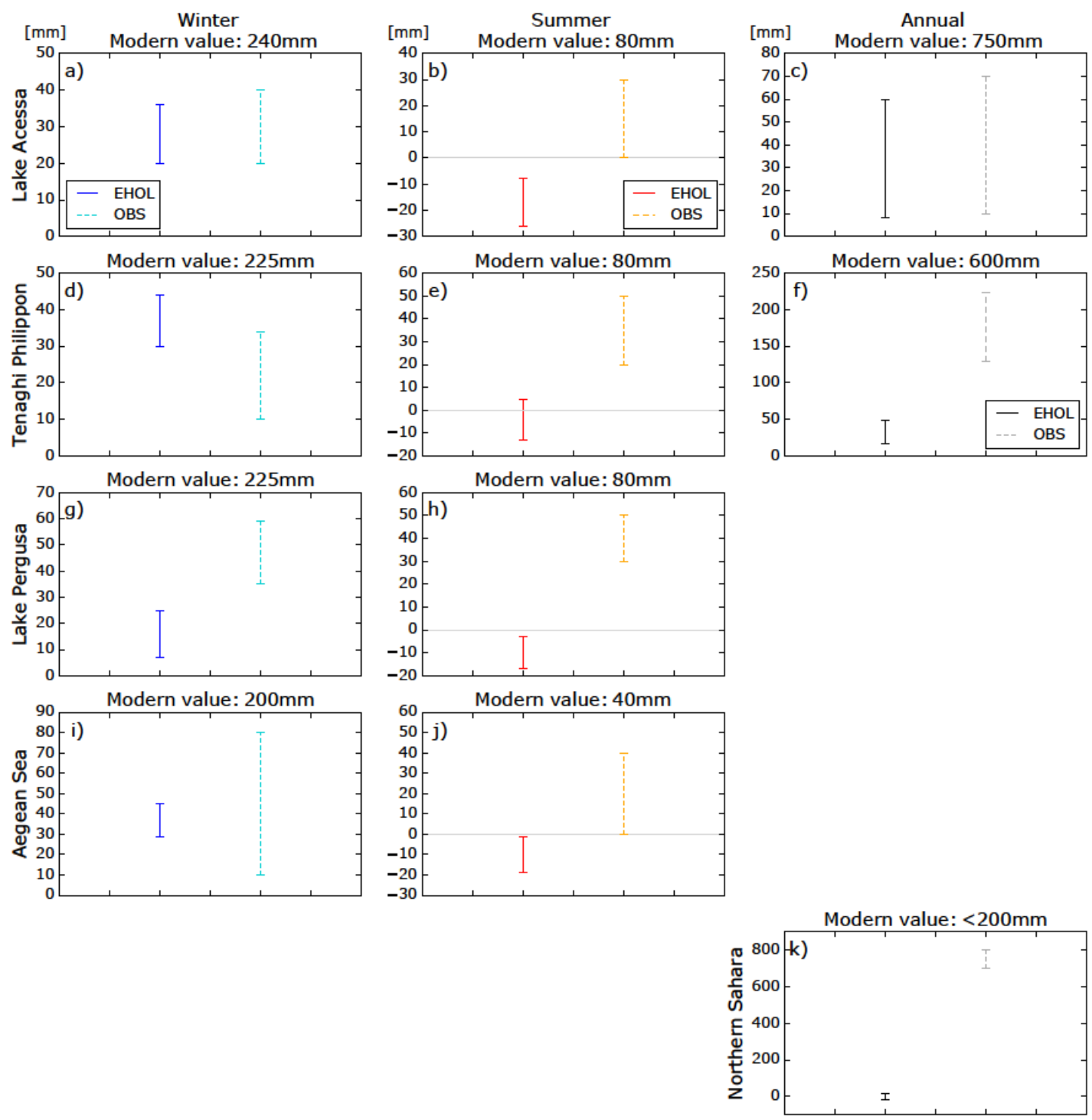
Figure S1: Model-data comparison for continental precipitation (solid lines $=$ EHOL simulation, dashed lines $=$ pollen data reconstruction). First row: Lake Accesa (Northern Italy) (Peyron et al., 2011), Second row: Tenaghi Philippon, (Greece) (Peyron et al., 2011), Third row: Lake Pergusa (Sicily), (Magny et al., 2013), Fourth row: Aegean Sea, (Dormoy et al., 2009), Fifth row: Northern Sahara (Bar-Matthews et al., 2003). First column: winter precipitation, Second column: summer precipitation, Third column: annual precipitation.
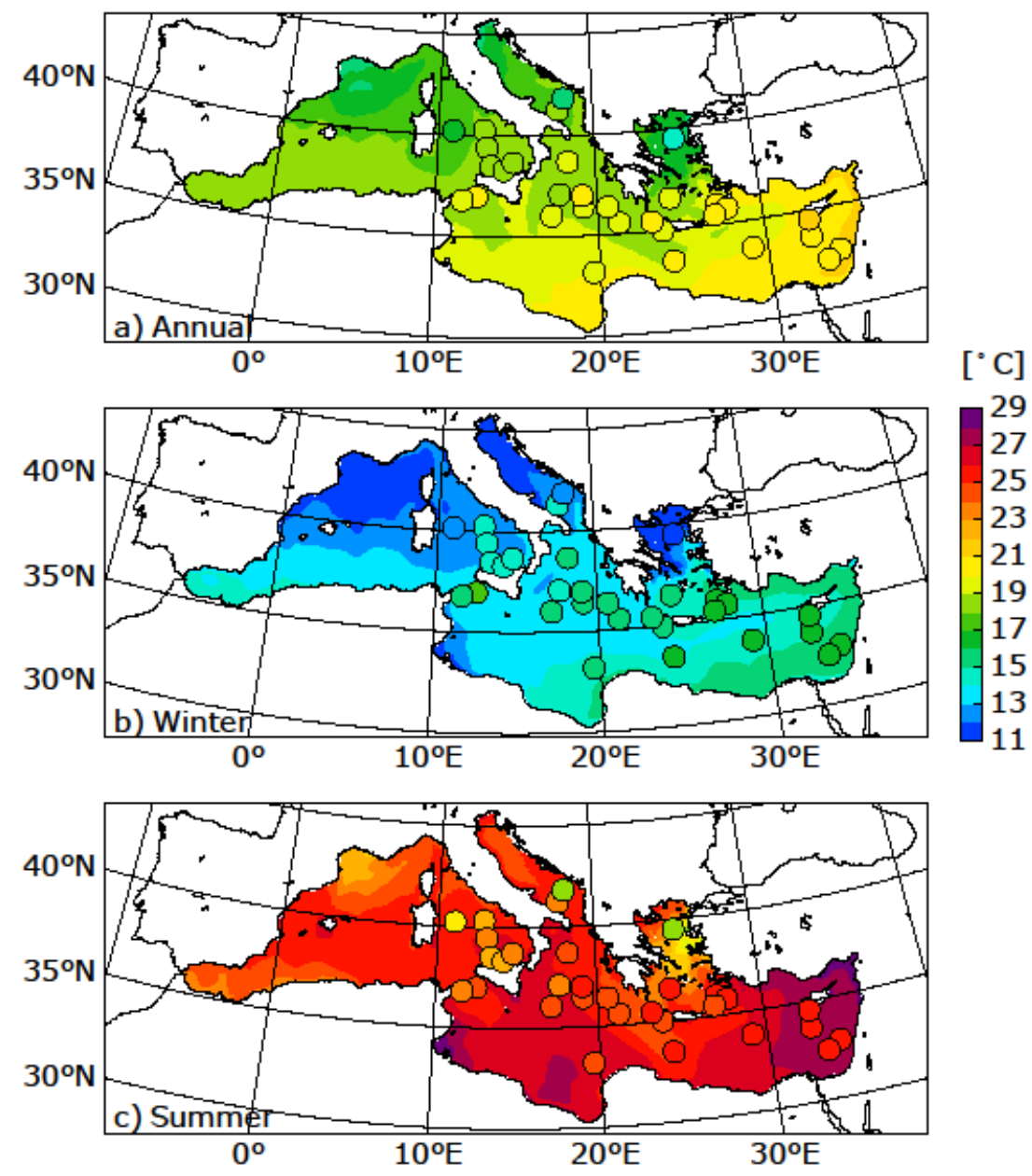

Figure S2: Model-data comparison for SST, adapted from Adloff (2011). Dots represent the unpublished synthesis of Kucera et al. (2011), published in Adloff (2011). The background colour represents the EHOL simulation. 


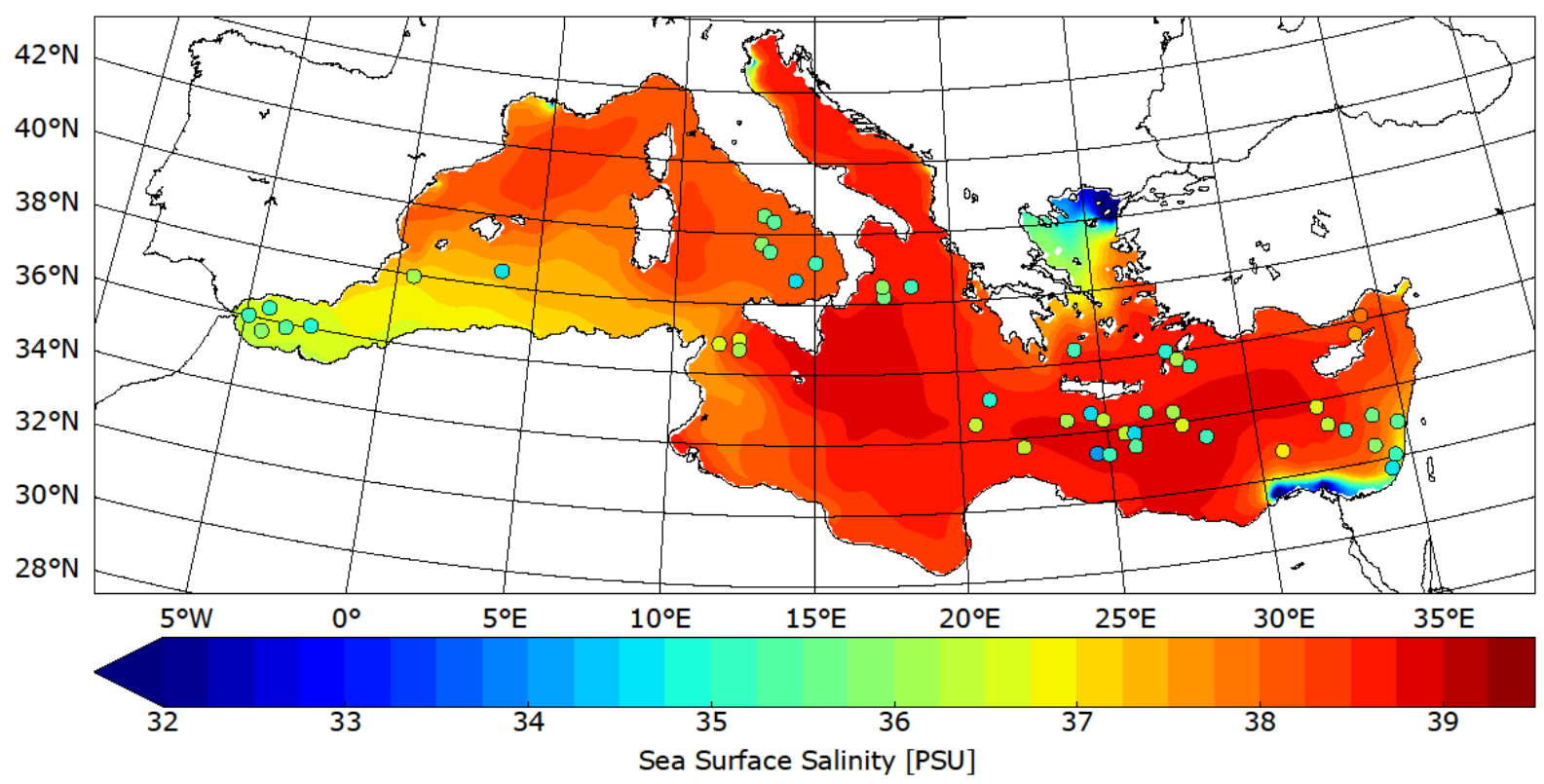

Figure S3: Model-data comparison for SSS. Dots represent the synthesis of Kallel et al. (1997a). The

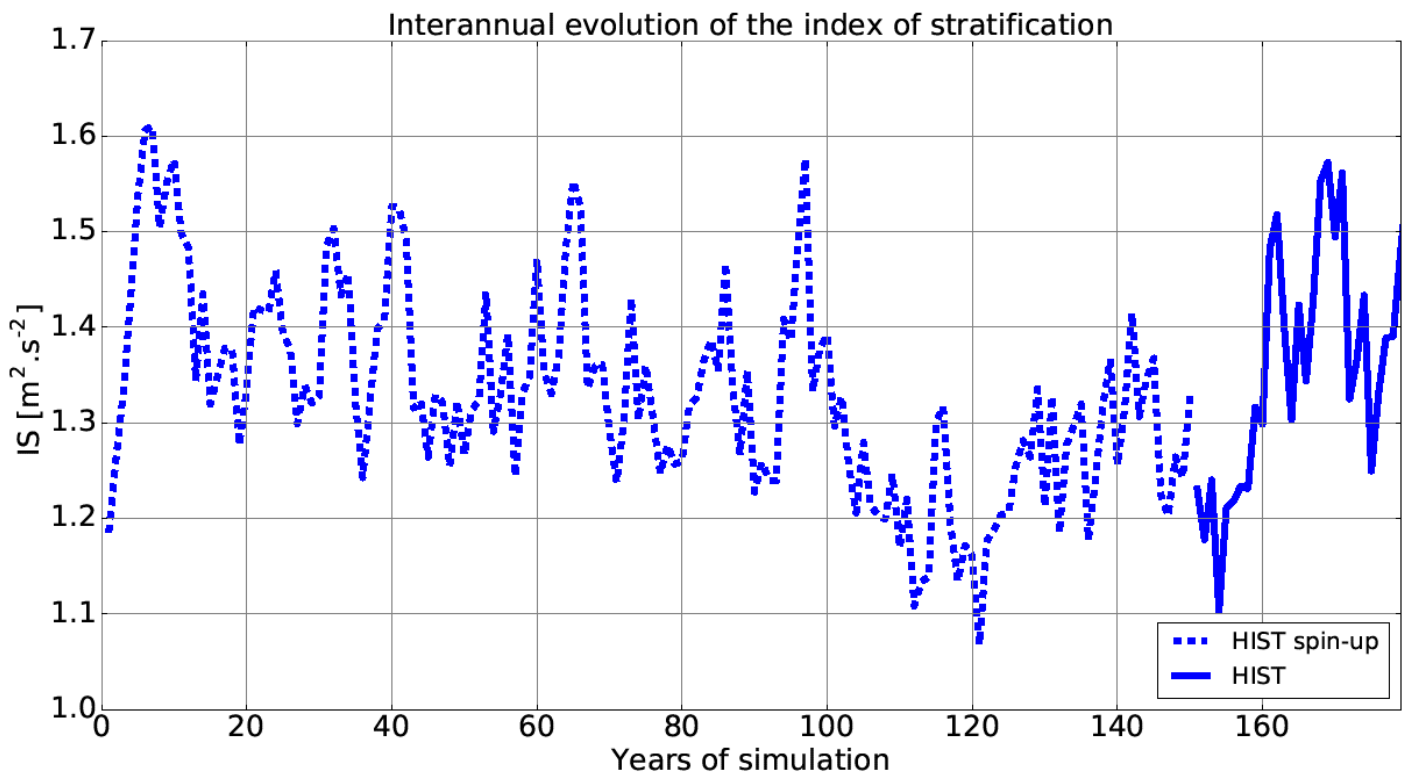

Figure S4: Interannual evolution of the index of stratification (IS) for the Mediterranean Sea for the

HIST simulation (including the spin-up phase). 


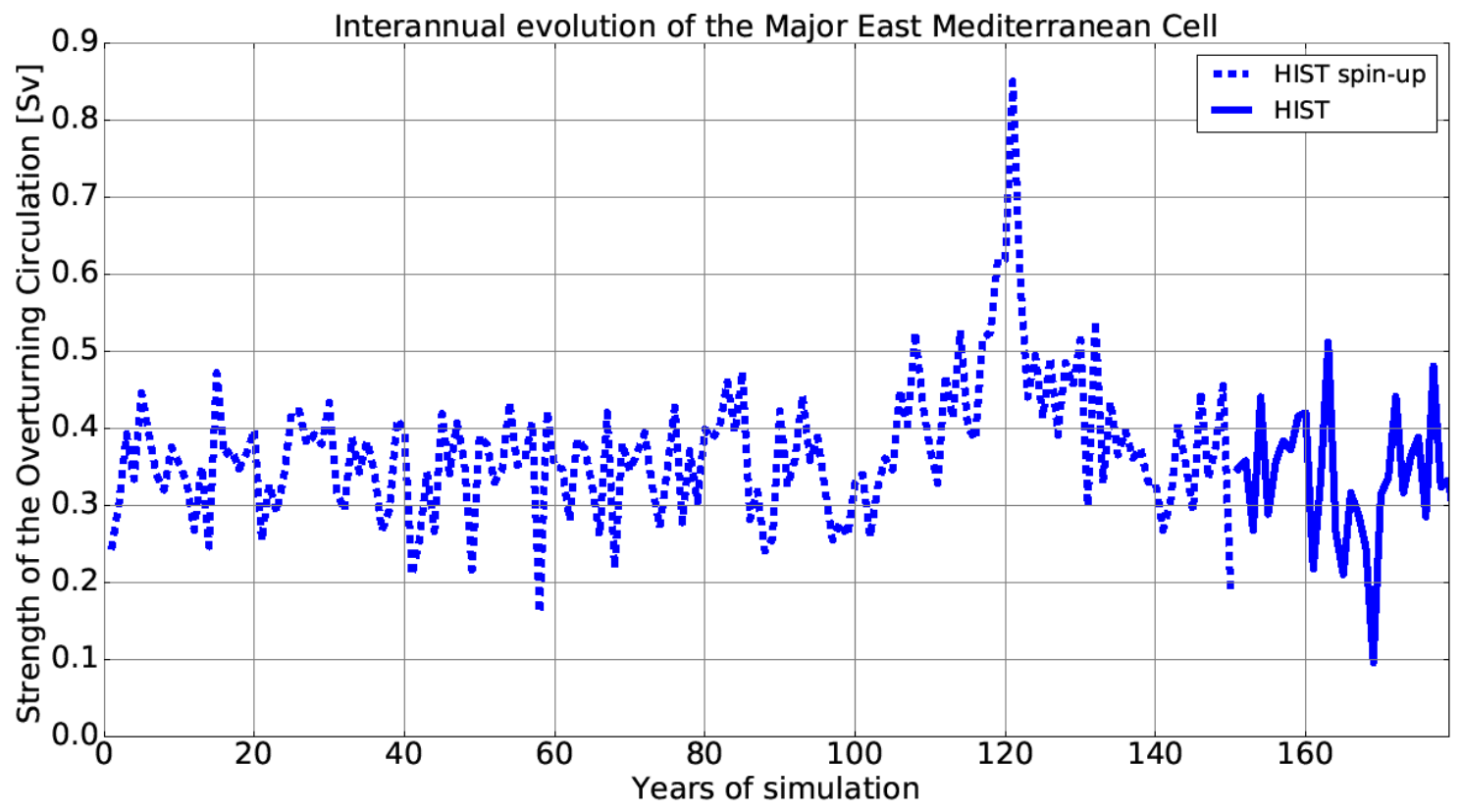

349 Figure S5: Interannual evolution of the Zonal overturning Stream Function (ZOF) in the eastern

Mediterranean Sea for the HIST simulation (including the spin-up phase).

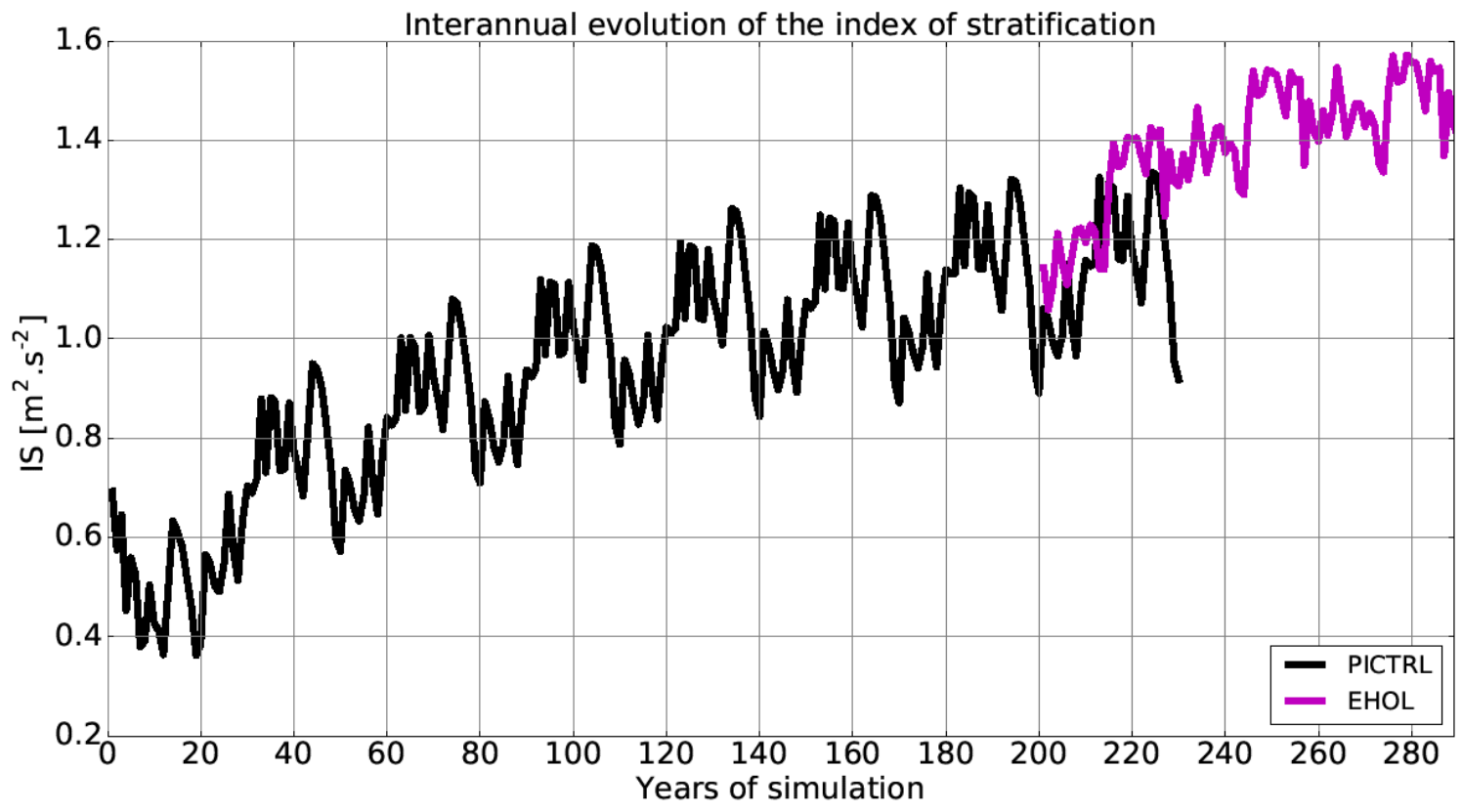

Figure S6: Interannual evolution of the index of stratification (IS) for the Mediterranean Sea for the PICTRL and EHOL simulations (including the PTCRL spin-up phase). 


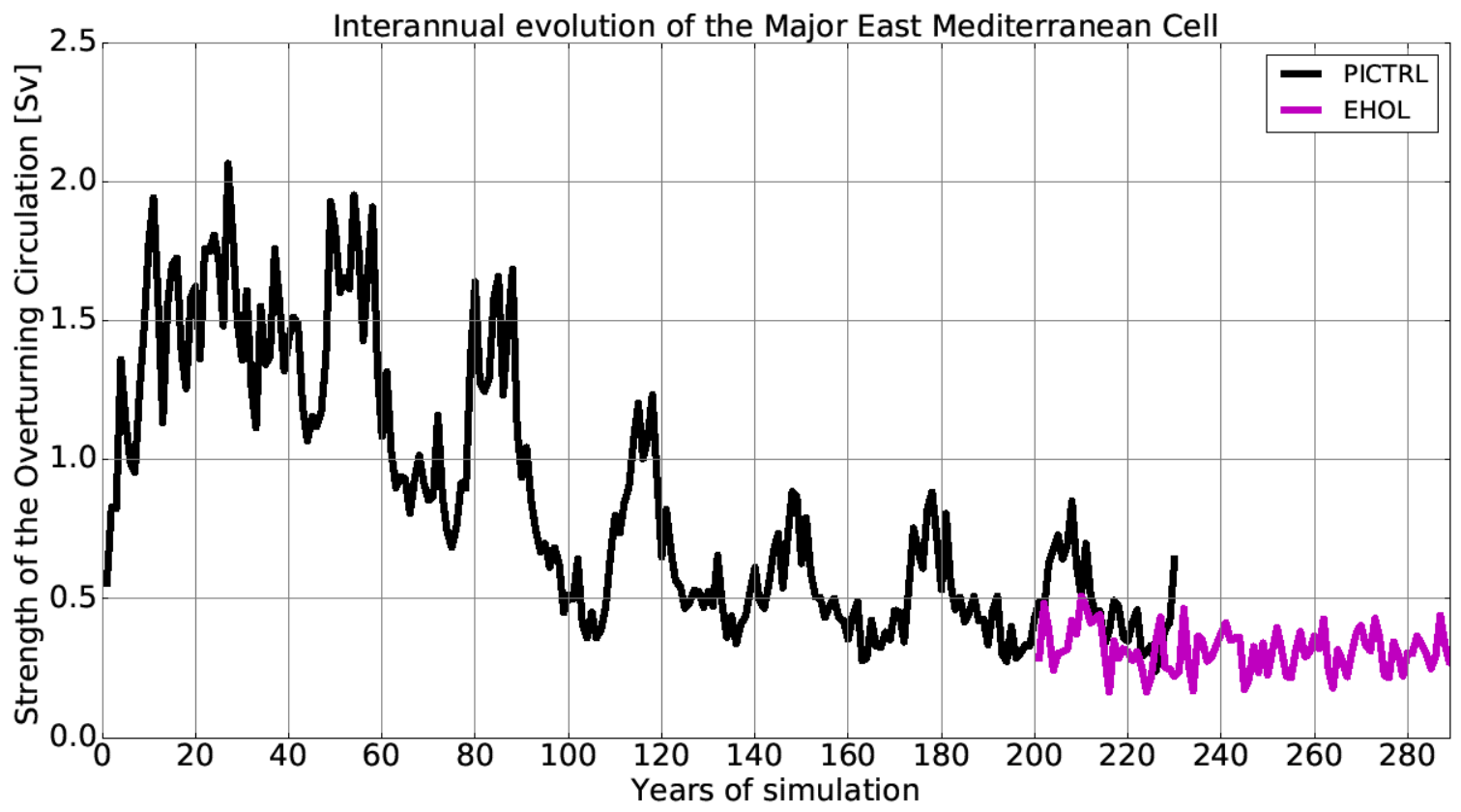

Figure S7: Interannual evolution of the Zonal overturning Stream Function (ZOF) in the eastern

Mediterranean Sea for the PICTRL and EHOL simulations (including the PICTRL spin-up phase).

\begin{tabular}{|l|l|l|l|}
\hline & HIST & PICTRL & EHOL \\
\hline $\begin{array}{l}\text { Orbital } \\
\text { parameters }\end{array}$ & $\mathrm{e}=0.01672$ \\
$\varepsilon=23.44$ & Idem & $\mathrm{e}=0.01935$ \\
$\omega-180=102.7$ & $\varepsilon=24.231$ \\
\hline $\begin{array}{l}\text { Atmospheric } \\
\text { CO2 }\end{array}$ & $\begin{array}{l}\text { Annual } \\
\text { observed } \\
\text { global mean } \\
(1970-1999)\end{array}$ & $280 \mathrm{ppm}$ & $280 \mathrm{ppm}$ \\
\hline SST forcing & $\begin{array}{l}\text { Era-Interim } \\
\text { monthly } \\
\text { forcing (1970- } \\
1999\end{array}$ & $\begin{array}{l}\text { IPSL-CM5A } \\
\text { picontrol + SST } \\
\text { correction }\end{array}$ & $\begin{array}{l}\text { IPSL-CM5A } \\
\text { early Holocene } \\
+ \text { SST } \\
\text { correction }\end{array}$ \\
\hline SIC forcing & $\begin{array}{l}\text { Era-Interim } \\
\text { monthly } \\
\text { forcing (1970- } \\
1999\end{array}$ & $\begin{array}{l}\text { IPSL-CM5A } \\
\text { picontrol + SIC } \\
\text { correction }\end{array}$ & $\begin{array}{l}\text { IPSL-CM5A } \\
\text { Early Holocene } \\
+ \text { SIC } \\
\text { correction }\end{array}$ \\
\hline
\end{tabular}


Table S1: Forcings and parameters used in both AGCM and ARCM. $\varepsilon$ is the elliptic orbit obliquity, e, 375 the eccentricity and $\omega$, the longitude of the perihelion.

\begin{tabular}{|l|l|l|l|}
\hline & HIST & PICTRL & EHOL \\
\hline $\begin{array}{l}\text { Buffer-zone T3D } \\
\text { \& S3D }\end{array}$ & $\begin{array}{l}\text { WOA monthly } \\
\text { forcing (1970- } \\
1999 \text { mean) }\end{array}$ & $\begin{array}{l}\text { IPSL-CM5A } \\
\text { picontrol + } \\
\text { T3D/S3D } \\
\text { correction }\end{array}$ & $\begin{array}{l}\text { IPSL-CM5A } \\
\text { early Holocene } \\
+ \text { T3D/S3D } \\
\text { correction }\end{array}$ \\
\hline River runoff & $\begin{array}{l}\text { Ludwig et al } \\
\text { 2009, Rivdis } \\
\text { database }\end{array}$ & $\begin{array}{l}\text { Ludwig et al } \\
\text { 2009, Rivdis } \\
\text { database (But } \\
\text { Pre-damming } \\
\text { Nile) }\end{array}$ & $\begin{array}{l}\text { Anomalies } \\
\text { inferred from } \\
\text { EHOL - } \\
\text { PICTRL } \\
\text { atmospheric } \\
\text { simulations } \\
\text { (NILE + East- } \\
\text { North margin) }\end{array}$ \\
& & & \\
\end{tabular}


Table 2: Forcings used in the ORCM.

\section{References}

Adloff, F., Mikolajewicz, U., Kučera, M., Grimm, R., Maier-Reimer, E., Schmiedl, G. and Emeis, K. C.: Upper ocean climate of the Eastern Mediterranean Sea during the Holocene Insolation Maximum A model study, Clim. Past, 7(4), 1103-1122, doi:10.5194/cp-7-1103-2011, 2011.

395

396

397

398

399

400

401

402

403

404

405

406

407

408

409

410

411

412

413

414

Bar-Matthews, M., Ayalon, A., Gilmour, M., Matthews, A. and Hawkesworth, C. J.: Sea - land oxygen isotopic relationships from planktonic foraminifera and speleothems in the Eastern Mediterranean region and their implication for paleorainfall during interglacial intervals, Geochim. Cosmochim. Acta, 67(17), 3181-3199, doi:10.1016/S0016-7037(02)01031-1, 2003.

Beaumet, J., Krinner, G., Déqué, M., Haarsma, R. and Li, L.: Assessing bias-corrections of oceanic surface conditions for atmospheric models, Geosci. Model Dev. Discuss., (December), 1-29, doi:10.5194/gmd-2017-247, 2017.

Dee, D. P., Uppala, S. M., Simmons, A. J., Berrisford, P., Poli, P., Kobayashi, S., Andrae, U., Balmaseda, M. A., Balsamo, G., Bauer, P., Bechtold, P., Beljaars, A. C. M., van de Berg, L., Bidlot, J., Bormann, N., Delsol, C., Dragani, R., Fuentes, M., Geer, A. J., Haimberger, L., Healy, S. B., Hersbach, H., Hólm, E. V., Isaksen, L., Kållberg, P., Köhler, M., Matricardi, M., Mcnally, A. P., Monge-Sanz, B. M., Morcrette, J. J., Park, B. K., Peubey, C., de Rosnay, P., Tavolato, C., Thépaut, J. N. and Vitart, F.: The ERA-Interim reanalysis: Configuration and performance of the data assimilation system, Q. J. R. Meteorol. Soc., 137(656), 553-597, doi:10.1002/qj.828, 2011.

Dormoy, I., Peyron, O., Combourieu Nebout, N., Goring, S., Kotthoff, U., Magny, M. and Pross, J.: Terrestrial climate variability and seasonality changes in thelrMediterranean region between 15000 and 4000 years BP deduced \rfrom marine pollen records, Clim. Past, 5, 615-632, 2009.

Guiot, J.: Methodology of the last climatic cycle reconstruction in France from pollen data, Palaeogeogr. Palaeoclimatol. Palaeoecol., 80(1), 49-69, doi:10.1016/0031-0182(90)90033-4, 1990.

Kallel, N., Paterne, M., Labeyrie, L., Duplessy, J. C. and Arnold, M.: Temperature and salinity records of the Tyrrhenian Sea during the last 18,000 years, Palaeogeogr. Palaeoclimatol. Palaeoecol., 135(1-4), 
417 Kucera, M., Rohling, E. J., Hayes, A., Hopper, L. G. S., Kallel, N., Buongiorno Nardelli, B., Adloff, F. 418 and Mikolajewicz, U.: Sea surface temperature of the Mediterranean Sea during the early Holocene insolation maximum, Clim. Past, 2011.

420 Locarnini, R. A., Mishonov, A. V., Antonov, J. I., Boyer, T. P., Garcia, H. E., Baranova, O. K., Zweng, M. M., Paver, C. R., Reagan, J. R., Johnson, D. R., Hamilton, M. and Seidov, D.: World Ocean Atlas 2013, Volume 1: Temperature, NOAA Atlas., edited by S. Levitus and A. Mishonov., 2013.

Ludwig, W., Dumont, E., Meybeck, M. and Heussner, S.: River discharges of water and nutrients to the Mediterranean and Black Sea: Major drivers for ecosystem changes during past and future decades?, Prog. Oceanogr., 80(3-4), 199-217, doi:10.1016/j.pocean.2009.02.001, 2009.

Magny, M., Combourieu-Nebout, N., De Beaulieu, J. L., Bout-Roumazeilles, V., Colombaroli, D., Desprat, S., Francke, A., Joannin, S., Ortu, E., Peyron, O., Revel, M., Sadori, L., Siani, G., Sicre, M. A., Samartin, S., Simonneau, A., Tinner, W., Vannière, B., Wagner, B., Zanchetta, G., Anselmetti, F., Brugiapaglia, E., Chapron, E., Debret, M., Desmet, M., Didier, J., Essallami, L., Galop, D., Gilli, A., Haas, J. N., Kallel, N., Millet, L., Stock, A., Turon, J. L. and Wirth, S.: North-south palaeohydrological contrasts in the central mediterranean during the holocene: Tentative synthesis and working hypotheses, Clim. Past, 9(5), 2043-2071, doi:10.5194/cp-9-2043-2013, 2013.

Peyron, O., Goring, S., Dormoy, I., Kotthoff, U., Pross, J., de Beaulieu, J.-L., Drescher-Schneider, R., Vannière, B. and Magny, M.: Holocene seasonality changes in the central Mediterranean region reconstructed from the pollen sequences of Lake Accesa (Italy) and Tenaghi Philippon (Greece), The Holocene, 21(1), 131-146, doi:10.1177/0959683610384162, 2011.

Rohling, E. J.: Environmental control on Mediterranean salinity and $\delta 18$ O, Paleoceanography, 14(6), 706-715, doi:10.1029/1999PA900042, 1999.

Rohling, E. J.: Paleosalinity: Confidence limits and future applications, Mar, Mar. Geol., 163, 1-11, doi:10.1016/S0025-3227(99)00097-3, 2000.

Vadsaria, T., Li, L., Ramstein, G., \& Dutay, J.-C.: Model and output for Vadsaria et al, "Development of a sequential tool LMDZ-NEMO-med-V1 for global to regional past climate simulation over the Mediterranean basin: an early Holocene case study”, GMD publication. doi:10.5281/zenodo.3258409, 2019.

Vorosmarty, C. J., Feteke, B. M. and Tucker, B. A.: Global River Discharge, 1807-1991, V. 1.1 (RivDIS), 1998. 